\title{
Summary Report of Working Group 1: Laser-Plasma Acceleration
}

\author{
C.G.R. Geddes*, C. Clayton ${ }^{\dagger}$, W. Lu ${ }^{\dagger}$ and A.G.R. Thomas ${ }^{* *}$ \\ - LOASIS program, Lawrence Berkeley National Laboratory, 1 Cyclotron Rd, Bemeley CA 94720, USA \\ ${ }^{\dagger}$ Departhent of Electrcal Engineersng. University of Cathornta, Los Angeles, Westwood, CA 90024, USA \\ "Department of Nuclear Engineerng and Radiological Sctences, Untverstty of Mtchigan, Ann Arbor, MI \\ 48109, USA
}

\begin{abstract}
Aduances in and physies of the acceleration of particles thing underdense plasma structursts doyen by lasers werc the topics of presentations and discussions $\mathrm{m}$ Working Group 1 of the 2010 Advanced Accejerator Concepts Workshop Swch

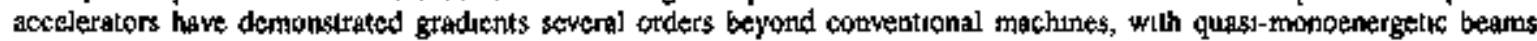
at MeV.GeV enkTgies, waking them atiractive candidales for noxt gethetaljon acceleralors Workshop discussions urcluded advances in control ower injectupn and laser propagation to further improve beam quality and stabulity, detailed diagmostics

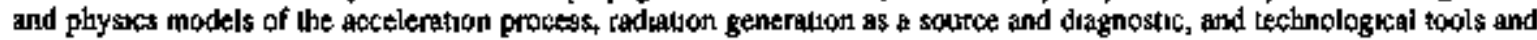
upcomung laciltues to extend the reach of laser-plasma acceletators
\end{abstract}

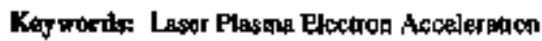

RCS: $5238 \mathrm{~K} d, 4175 \mathrm{w}$

\section{INTRODUCTION}

Working Group 1 (WG1) explored laser-driven acceleration of electrons and postrons in underdense plasmas, and the related topkcs of laser propagation and dagnostics This includes laser wakefield acceleration [1], where acceleration by a plasma wave excited by the laser recently has been demonstrated to produce intense beans of eloctrons at MeV-GeV energies with percent energy spread and with gradients three orders of magnitude above conventional systems [2-9], and drect acceleraloo [10] where particles are drectily accelerated by a laser pulse shaped by a plasma structure providing a linear mechanism with potental to harmass low-energy laser systems [11] With demonstraluon of high eatrgies and gradients over the last several years, the focus of discussions was on control, detalled dragnostics and physics models, and technological tonls to work towards the beam qualitaes required by appications For high energy physics colliders at the TeV scale, this included how very low beam emitance can be obtaned/preserved and staging/beam transport, and for novel and compact radiation sourses, how these can be uniquely or advantageously dnven by laser plasma accelerators

The working group hosted eleven sessions, with thirty-nine oral presentatuons, including jount sessions on radiaton generation and sımulations and with the beam driven plasma group, and nıne poster presentations supportıng wotkshop discussions on recent experimental and sirnulation results, and on the physics mechamisms for contimued unprovement in beam quality and energy These sessions were organuzed around discussions of the following questuons

- How should unjection into the structure be controiled for reproducible beams with low emutance?

- How can laser propagation and accelerator structure be controlled for high beam qualily and efficiency? How do we stage modules to reach high energles? (Joint with beam dnven woakıng group)

- How can laser-plasma acceleraled beams generate unique radiation sources, and what insight does such radiation prowide on the accelerator? (Jount with radration working group)

- What diagnostic techniques allow us to understand the physics of beam produchon and acceleratıon, and laser evolution?

- How can simulatuons and theory address the requred physess and design expetıments, and where are improved diagnostics or methods needed? (Joint with computational working group)

In addition, techniques for controlling electron beam propagation were drscussed as patt of the radiation source session, which are also important to staging multiple modules to achıcve hugh energies Plans for new facrlutues designed to 
push the energy fronter atd to develop new techtugues for control were also discussed This summary paper presents hughlughts from each of these discussions, outlining the proceedings of the workung group In many cases, $\theta$ paper presented results relevant to many of the topics, and may appear more than once in the following Detaled results and references may be found in the respectuve papers in these proceedings

\section{INJECTION CONTROL}

The qualıty of the intual injected particle bunch, and control over the trepping process, are vital to obtaining high qualtty beams, and are a topic of mtense research covered by the working group This is because, th the absence of darnping nngs or other special techniques used in colliders, the acceleratrng structure at best preserves bunch emittance such that a low enuttance injector is required Simularly, the injector must be controlled to inject the appropraate Iongitudinal busich shape at the comest phase in the structure such that asceleratton, including beam loading and dephasing, will produce narrow energy spread Progress was presented on controlling irjection using a vanety of rechniques, Including refinement of the controlled self trapping which first produced monoenergetuc beams in such acceleraturs, and controlled trapping via colliding laser pu[ses, 1onzation, and shaping of plasma or applied magnetsc fields

Self trapping, which occurs when the wakc reaches an amplitude sufficlent to trap electrons from the plasma through which tt propagates, has been used sunce early experiments, and refinement in understanding and control of this process conbnues While broad energy spread beams were produced in early expenments ([12] and others) which drove the wake far atove the trappung threshold and/or did not control acceleration length, it has been demonstrated that appropnate control of laser and plasnia parameters (amplitude just above the trapping threshold, and exiracting the bunch as it is momentum compressed by dephasing from the accelerating fiekd) can generate bunches with few percent energy spread and mrad divergence $[2,3,4,13]$ Stable operation at up to $\mathrm{GeV}$ energies has been observed $[5,8]$ Several presentations addessed the theory of this injection process, uncluding trapping threshold atd bearn quality General trapping condrtions for non-evolving wakes were presented by We1 Lu of UCLA, grving a physical preture of injection Simulations were used for verfication of the physical picture by utilizing tron-evolving beam dtivers This method was then used to charactenze the effects of dnver shape and plasma chaniels Analysis of the trapping condition in a bubble was also denved by Alec Thomas and presented by Sluart Mangles by analyzing trajeclories in a comoving frame with the bubble, which is assumed non-evolving on the time scale of injection (though ewolution of the laser up to the injection point is taken unto account) Good agreement with expesiments from Impertal and LLNL was shown Two talks addressed the effects on injection of evolution tn the bubble structure dnven by intentional laser spot

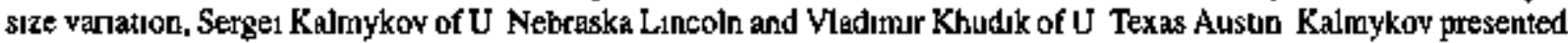
stmulations showng that an intially 'over focused' laser pulse diffacts to a stable self guided rudus at which ut then propagates Durung deffraction, the bubble tadius and length expend, rapping particles that would otherwise not be trapped (suxch an effect is also produced when the plasma density decreases [14, 7]) Simulations using the quasi-statıc code WAKE with add-on non-quasistaluc 'iest' electrons to simulate injection (prefened by some for nouse reasons) gave reasonable agreement with full PIC under these conditions, neglectung beam loading of the structure which was not serere Kalmykov and Khudik each presented a Hantltonıan model of trapping in such evolving bubbles Khuduk presented test-particle models of particle trajectores illustrating the role of expansion, and showing which particles are trapped The difference betwen accelerated and trapped particles was analyzed He found that the 'burmp' in electron density caused by re-conwergence of partacles at the end of the bubble had a signficanl effect in lowenng trapping threshold relative to ideakized circular bubbles The working group hosted discussion and companson of each of these theones While the first two 1alks found trapping criteria without lasey evolution, the latter two found that bubble evolution was critical to injection, and this remains a topic of discussion as does the relative ment of quasistatic with add-on particles versus full expitict PIC (which seif consistently handles injection) for these problems

Improved understanding is faclitating control over self uapping Results on productuon of slable $200 \mathrm{MeV}$ electron bunches from self trapping using a gas cell were presented by Stefan Karsch of LMUMPQ A varuable length gas cell was atso used to charactenze dephasing effects A new laser system at MPQ 18 producing high power pulses at $8 \mathrm{fs}$, allowing resontant excttatıon of plasma wakes at high dentsities, and has demonstrated production of $25 \mathrm{MeV}$ batnches with 3 \% energy spread using only $70 \mathrm{~mJ}$, as presented by Laszlo Veisz The self trapping threshold was characterized as a function of plasma density in experiments at LLNL presented by Bradley Pollock, and in a related plenary by Froula wheh also presented an overvew of other experıments Several other groups presented data on self trapping and its relation to laser spot evolution and synmetry, which are covered in the sections below 
To further improve bunch momentum spread and stability, the working group hosted discussions of significant advances in separate costrol over electron injection into a wake driven to an amplitude below the self trapping threshold, so that injection and wake structure can be tuned independently. This can be important to allow tuning of the wake structure into regimes that would not produce trapping, and may also reduce the transwerse momentum spread that results in self trapping because particles are trapped from the transverse edges of the bubbie. Coiliding pulse injection uses the beat between two nearly counter-propagating laser pulses to give electrons a kick in phase and momentum into trapped ortits th the wake of the driver, and the charge and injected location of the injected electrons are controlled by the beat amplitude and location $[15,16,6]$. Experiments and sinulations at LOA were presented by Victor Malka, demonstrating stable beams near $200 \mathrm{MeV}$ with 5 \% energy spread (limited by specirometer resolution in this case, down to $1 \%$ having been shown in other cases) and encrgy tuning from 50 to $220 \mathrm{MeV}$ using a smallangle collision and $32 \mathrm{TW}$ dive power near $a_{0}=1.5$. Charge and energy spread were found to be comrelated when tuning with collider strength or plasma density, and beam loading and injection phase space effects were characterized using simulation and experimen1al scant. Experiments at LBNL were presented by Guillaume Platean, showing control over injection viz beam timing, plasma density, and colliding pulse intensity, and demonstrating the use of computer controlled active boam pointing feedback to achieve reproducible injection ower hours of operation. The experiments use a $10 \mathrm{TW}$ driver with $a_{0}>2$ at a $19^{\circ}$ angle, investigating injection into nonlinear wakes, and guiding of the driver pulse has been demonstrated in preparation for guided colliding pulse experiments. VORPAL simulations used to design these experiments were presented by Estelle Comier-Michel of Tech-X, and successfully predicted the plasma density and laser regimes for best injection observed in the experiments, as well as timing behavior. Effect of non-ideal laser modes and laser focal location and self-focusing in the plasma channel on the trapped bunch were evalualed. For optimized parameters, accessible to the experiment, a $20 \mathrm{pC}$ electron bean can be accelerated to $300 \mathrm{MeV}$ with percent level energy spread, twice the energy avajlable from self-injected experiments on the samte system.

The use of ionization to control injection into the wake [16-19] has been an area of intense research since the last AAC conference, and six presentations reviewed theory and experimental results. In this tochnique, a gas or gas mixture is used which has ionizalion states near the peak intensity of the wake drive laser for injection and ideally a large gap in intensity down to the next (bulk) group of states. In this cast, the leading edge of the driver at low intensity tonizes the bolk states producing a plasma in which the wake is driven. The last state(s) are ionized near the peak of the laser palst, injecting electrons at nearuzero velocity into the wake at a phase where the bulk wake oscillation velocity is negative, and oear the zero-crossing of the electric field. These electrons can hence be trapped more easily, at lower driver intensity, than the bulk plasma, Ionization trapping beory and VLPL simulations were presented by Min Chen of LBNL, showing the required wake amplitude for trapping of these electrons, and the behavior of injection and beam phase space was characterized with verious gas mixtures and lengths. Optimum beam energy spread less than $0.5 \%$ is found for short mixed gas injector regions and few-percent mixtures of, for example, $\mathrm{N}$, in $\mathrm{H}$ bulk gas followed by a pure $H$ plasma for acceleration, and laser pulse skew was shown to futdher improve spread. Optimum enitlance was found for intensilies just above the ionization threshold. Theory showing the optimal injection phase and an analytical model for trapping and subsequent energy gain were presented along with experiments conducted at UCLA by Arthur Pak. The experiments showed $100 \mathrm{MeV}$ electron energy gain with broad energy spectra for parameters where there is no self trapping and were analyzed through comparison with OSIRIS simulutions. Bradley Pollock presented experiments from LLNL using $\mathrm{He}+\mathrm{CO}_{2}$ gas mixtures in which a broad energy spread with electrons up to $1.5 \mathrm{GeV}$ was observed using a $200 \mathrm{TW}$ laser in a plasma at $1.3 x] 0^{18} / \mathrm{cm}^{3}$ density [21]. Both of these experiments observed broad energy spread, with the highest beam intensity at low energy, attributed to continuous injection and acceleration over less than a dephasing length. Pollock also described dosignts of a two-stage gas cell, with a $500 \mu \mathrm{m}$ mixed gas followed by a longer pure He region, and simulations showing that this design is anticipated to achieve narrow entergy spread bearns near $1.5 \mathrm{GeV}$. Experiments at Michigan characterized effects of variation in mixing concentration and species, as reported by Chris MoGuffey. At and $\mathbf{N}$ doping into He gas resulted in increased charge and lowered divergence as well as reduced threshold density for injection. At 100 TW laser powers, quasi-monoenergetic beams were glso obserwed near $200 \mathrm{MeV}$, though with brogder energy spread than self trapping. Experiments at LBNE were described by Kei Nakamura, in which stable quasiononoenergetic beams al $13 \mathrm{MeV}$ with shot-to-shot fluctuation of only $0.6 \mathrm{MeV}$ ower 1000 shots were generated in min-scale gas jets with $1 \% \mathrm{~N}$ in $\mathrm{He}$ near $3 \mathrm{xl}^{18} / \mathrm{cm}^{3}$ dersity using a $30 \mathrm{TW}$ laser, and with minimal depletion of the drive laser pulse. These beams are suitable as an injector and tuning of injector charge and energy was demonstrated towards their use with chatllary structures. JAEA results presented by Hideyuki Kotakj demonstrated improved pointing, divergence, stability and peak energy in Ar and $\mathrm{N}$ gas jets. Ower $100 \mathrm{MeV}$ energies were demonstrated from a 3 TW laser, and beam steering using the gas jet transverse pasition (und hence transwerse plasma density gradients) was shown. 
A vanety of other injection methods were discussed, including further results on plasma density gradient trappiag $[14,7]$ A double gas nozzle incorporaling a small and a large outlel, which produces a modulated densily profile sutable for downramp trapping expenments, was presented by MoGuffey An asyumetncal supersonic jet exhibiting strong shocks was shown whuch may be applicable to density down-ramp trapping techniques was presented by Tomonao Hosokar of Osaka Talored capillanes incorporaung gas jets, and use of Ramat scaltering to measure the resulting density modulation with benchmarking to gas flow simulations were presented by Karsch Use of a shatp density transition produced by a shock in a gas jet, followed by a utuform plasma region, was shown to stabiluze injection and reduce energy spread by Vessz, producing $27 \mathrm{MeV}$ bearns with $26 \%$ energy spread and $4 \mathrm{MeV}$ energy stability

\section{GUIDING AND ACCELERATOR STRUCTURE CONTROL}

In a laser-plasma accelorator, the accelerator structure is formed by the self-consistent interaction of a laser propagatIng in a plasma To preserve high bunch quality during acceleration, the laser and plasma profiles must be shaped such that the accolerator structure has the desired amplitude and shape, and to control evolution of the structure as the laser propagates For wakefield accelerators the workang group included discussions of the effects of non-udeal laser modes, of leser guiding tsing capillary discharge [22] and wall gutding [23] structures and relativistic 'self' guiding [24], of methods to structure the plasma density for injection control, and of advanced techniques for controlling the laser mode and plasma shape to increase performance For high enetgy applications [25], staging of multiple modules 1n sentes is also begining to be approached In a direct laser acceleration scherme, lower laser powers are typical such that relaturstic self guiding is not promunent, but the struclure must be modulated to keep the laser field and particles correctly phased, and such structures were also addressed [11]

The effects of non-Gaussian laser modes and optical aberratoons produced by high-power laser systems were a focus of discussion While theorelical derivations of accelerator structure, and past simulations, have typically used the lowest-orter Gaussian laser mode, experimental high-power lasers have high-order mode contenl which causes spot asymmery and devation from the Gaussian profile The effects of Jaser mode guality on injection and acceleration In capilary wavegujdes at the Astra Germun laser were presented by Simon Hooker (Oxford), showing that use of an uns reduced mode aberration producing a relatively clean mode with approxumately half the ethergy This reduced laser energy threshold for injection two-fold, indicating that the energy in the central spot controls injection This was confirmed by simulations presented by Nicolas Bourgeous (Oxford), which showed that the spot energy, nol mode size, effect of the urs was domunant In expertments at the Lund laser center presented by Stuat Mangles (Imperial), controlled aberrabons were introduced resulting in an increase in beam divergence and injection of off-axis bearns, demonstrating directly the importance of spot quality Injection threshold density was then characterized as a finction of laser power and focal spot quality, showing that energy in the central spot not total beam erergy is the parameter controlling injection in agreement with the Oxford results. Pulse compression by the plasina wave was also characterized Related work by the CNRS group is noted beiow The effects of realistic nodes are also being analyzed through sImulation, and work by Estelle Cormler-Michel using the VORPAL code compared acceleration with reslistic laser modes from LaNL experiments to udeal Gausstans for colliding pulse injection This isolates the effect of laser mode on injecuon and structure, and showed that, even for high quality modes where $\sim 90 \%$ of the bearn 18 נ 1 the cenlral spot, the effoct of aberrations can still be significant for both charge and beam energy, indicating that very high quality spots will be required to achseve optımal performance

To achteve high entrgies, acceleration over distances much grealer than the laser diffractom range $Z_{R}$ is required, which relies on laser guiding by preformed channels and relauvistic self guiding, and their interactons This was the focus of several talks in self gurding the self-consistent modification of the plasma refractive index introduces a guidng effect for sorne parameter regimes Preformed channels can further extend guiding regines, and include discharge capillarses where strikng a discharge in hydrogen gas creates a transwerse density gradient by heat conductoon whuch provides guiding, and wall guidıng in capillanes without density shaping Expenments by Oxford at Astra Gemun (S Hooker) investgated the telative importance of channel and gelf guiding in discharge capollary plasmas by scanning the time of amval of the laser pulse with respect to the discharge to vary the guiding profile They foutid that at high densities trapping and acceletstion could be achueved at any timung, consistent with stable self guidıng as predicted by theory At lower densities, the waveguide profile is required to achieve injection and acceleration. as expected, and it is in thus regime that the bighest qualıy and energy beans were observed This was supported by WAKE simulations (Bourgeousis) showing that the charnel contribution prevented diffraction and allowed stable propagation and was important even for cases where the laser spot was smaller than the channel matched spot size 
Discharge capillary experiments at LBNL showed that the transverse displacement of the laser spot at the channel exit, and its dependence on timing of the discharge and the input displacement, provides a precise diagnastic of the waveguide transverse plasma density profile. This improved channel profile data confirmed simulation predictions of channtel profile and scalings with parameters, providing important data to desige of future experiments. Discharge capilkary guides using glass media (others use Sapphire) developed at Utsunomiya University, Japan were presented by Hiromitsu Tetauchi. Plasma parameters wese measured by an interferometer and a hydrogen plasma tine spectrum. showing temperature of $3.3 \mathrm{eV}$ and density near $10^{17} / \mathrm{cm}^{3}$, and guiding was demonstrated using a low intensity laser pulse. Hydrogen filled wall-guiding capillary stnuctures were investigated in the linear wake regime at CNRS France as presented by Brigitte Cros. Sirnulations were conducted showing that the laser mode must be centered in the capillary within $30 \%$ of its radius, in agreenent with measurements, and that input angle and mode must also be controlled to achieve high quality guiding. Experiments at the Lund laser then implementod and evaluated melhots for controlling beam pointing onto the capillary, showing that mechanical improvements and inhibiting shots during unstable parts of the $10 \mathrm{~Hz}$ cycle tact gained $\sim 20 \%$, and that active pointing with a pilot beam gained a further $\sim 15 \%$. The focal spot was then controlled using a deformable mirtor and wake amplitude in the capillary deduced from spectral shifts in the laser, and comparison of these tesults with simulations allowed inference of accelerating fields of $1-7 \mathrm{GV} / \mathrm{m}$ at densities of a few $10^{17} / \mathrm{cm}^{3}$. Simulations demonstrating designs for multi-GeV experirnents on the Texas Petawatt laser were presented by Xiaoming Wang of $U$. Texas.

Techniques to funther control plasmin shape and laser propagation include control of the pre-plasma crealed by the laser before the main interaction [26], and gas jets with shaped profiles [7]. Shaping of the pre-plasma using an applied axial magnetic field was discussed by Tomoneo Hosokai of Osak, showing that fields of $\sim 0.2 T$ shaped the jreplasma into a funnel shape. The prepulse level was adjusted by aligning the compressor, and combination of these techniques improved laser focusing and propagation distance through the subsequent plasma, producing quasi-monoentergetic beams at $J 00 \mathrm{MeV}$ and improved stability versus exponential spectra at lower energies with uncontrolled prepulse. Related experiments on the role of coaxial nagnetic field were presented by Will Schumaker of Michigan. Gas jets are targets for many laser plasma experiments, and are now being used willhin capillary plasmas to tailor the density profile along the laser propagation direction allowing a high density injector within a long low density stnucture. A fast valve is important for such applications to reduce gas loading and discuption to the capillary stricture, and results on an electromagnetically driven valve were presented by Mahadevan Krishman of Alameda Applied Sciences Corp. The valve, actuated by a flycr plate, opens in $\sim 100 \mu s$, significantly faster than fraditional valves at the required pressures. The mechanism provides scaling to 10 's of microsecond opening times, and can operate larger apertures. A new version of the valve is under development to create shaped jets.

For high energy physics applications where $\mathrm{TrV}$ energies and beyond are desired, it has been envisioned that staging of multiple accelerators in series will provide the hightest system gradient and also may be desirable for busch charge considerations [25]. This is because, as single stage energy gain is increased, the accelerating gradient drops while bunch charge and laser entergy increase so that a single - slage TeV accelerator would have lower gradient. To realize the benefits of staging, it is crucial to couple the stages as closely as possible to maximize geometric gradient. Experiments on plasma mimors to achieve close coupling were presented by Thomas Sokollik of LBNL, showing that tape drive based mirors can sustain higb rep rate operation and provide $80 \%$ reflectivity, and that optitmum compromise between mode quality and refectivity is near $1 \times 10^{16}$ W/ $\mathrm{cm}^{2}$. Tape roughtess, beam quality, and pointing stability were characterized.

Use of laser plasma accelerators for many applications demands improvements in both energy transfer from the laser to the beam, and in the enittance of the beans (in particular to meet the MW beam power and nm emittance requirements of future colliders), and advanced techniques to achieve these goels were discussed. Plasma density tapering [27] is a technique to compensate phase slippage of the accelerating particles when their velocity does not match the driver, and hence exiend acceleration to laser depletion, improving efficiency. Simulations and theory demonstrating use of tapering to improve energy gain were presented by Antonio Ting of NRL including bucket jumping, where the detsity is suddenly shifted to switch the particles to a new wake period. This can further extend the acceleration distance if not limited by laser depletion, and in particular was applied to acceleration of moderate energy $(9 \mathrm{GeV})$ protons where it is important for high gain because the particles are relatively low $\beta$. Other approaches for proton acceleration such as near-critical densities and beat waves to slow the wake were also characterized. To improve and control the transverse emittance of the beam, and to efficiently accelerate positrons, the focusing fields and their phase with respect to the accelerating fields must be controlled. Antlytic theory showing this can be achieved in the litear regime by shaping the transverse laser mode, and VORPAL simulations demonstrating quasilinear operation and that the required high order modes propagate stably in plasma charntels (from [28]) were prestented by Cameton Geddes of LBNL. These simulations showed that the transverse fields can be reduced to atlow acceleration of a 
very low emuttance beatn while keepsng the beann sIze Jarger than in the Gaussian laser case, whuch was shown to be important to allow acceleration of bigh charge beams without inducing blow out of the wake The phase of the acceleratung and focusing ficlds can be controlled using mode ratio and delay which is the subject of ongoing work to compensate beam loading

For direct laser acceleration the phase slippage length is much shorter than in walceficld acceleraton since a particic cxpertences acceleratron over a fraction of a laser wavelength, not a plasma period Hence quass phase malching where the density is modulated such that once the particle slups frorn accelerating phase, the wave is te-phased to put it back in acceleraang phase of another perıd [11] - akın to bucket Jumping - is crucial to achieve hugh energy gaun, and techniques to achieve thus were presented by Bnan Layer of $U$ Maryland Two techniques for malang the reguired plasma channels which have both a transwerse density gradient to provide guiding and an axial density modulation to allow quasi phase matchung were developed The first uses a nng grating to radially modulate the 100 ps chantel formung laser putse which is then focused by an axkcon to a line focus where the radial medulation becomes an axial vanation in intensty Using such a beam to illuminate a cluster fet produced modulated guides with maxima at the maxima of laser unlensity, and such structuires were shown to guide a probe laser pulse Alternatively, remioving the ring gratıng. modulation was produced by placing a wire 'comb' across the cluster jet extr to create periodic regions free of clusters, allowing very fine longitudinal control The ID rathal-like modes required for the guzded laser to produce an acceleratung field were generated by inserting a half pellicle into the beam, shifting half of it by $\pi$ phase. and an experimenl to demonstrate accekeration is in progress

\section{RADIATION JOINT SESSION}

An important potennal application of the electron beams produced by etther laser or bean driven vrakefield accelerators is in geteratsng briltant sources of radiation In a jout session with Workang Group 5, Bean and radiation generation, monztonng and control, a large number of groups reported on advances in radiation prodiction, meacutements and modeling from the oscillations of telatuvistic electron beams produced by laser wakefield accelerator The radiation measurements that were reported were produced manly in two ways, ether by oscillations of the elections in externat magnetıc undulators $[29,30$ ] or by betatron oscilations in the transverse fields of the wakefelo itself [31] Athother radiation gentralion mechanism, backscattering a laser-pulse from the relativistic electron beam [32], was also discussed - un partcular by Utrich Schramm relevant to a future upgrade of the FZD laboratory to enable such expenments - but no experimental results were repoxted

The reported results show that constderable progtess has been made, with many orders of magnitude increases un the bnlliance and energy of the $x$-rays from the betatron source, in addition to technological steps being made towards a table-top free electron laser using atl exterial undulator and new radiation dagnostics, both expenmental and numencal The LWTA betatron source has now been charactenzed by a number of groups and the radiation emssion has been shown to achieve a peak brightness comparable to 3rd generation symchrotron light sources, althourgh the average bnghtness is lower due to the currently low repettuon rate Radiation generahon from a LWFA-produced beam un an external undulator has also been measured [30]. which may potentially pave the way towards compact freoelectron-laser light sources The interesting aspect of the laser produced olectron source, as opposed to a conventional acceleratot, is the prospect for extremely short electron bunch durations Hence, electron bunch duration measurements are of significant interest, as a short electron bunch enables short raduation pulse duratuon

Stefan Kneip presented measuremets of betatron $x$-try properties from experiments by a collaboration of the Impetial College London and University of Michigan using the HERCULES laser system, demonstralung a 1.100 keV $x$-ray soure whth $1000 \times$ greater peak brightmess than previous laser drven betatron sources This was prncipally due to the sigtificantly higher electron team energies compared with previous results The source was also shown to have an appreciable degree of spatal coherence, which was inferrod from modelung of Fresnel diffiaction of the radiation from a cleaved cryslal Th1s enabled phase-contrast $x$-ray inages of biological material using photons wilh a $\sim 10 \mathrm{koV}$ cnical energy to be taken Betatron $\mathrm{x}$-ray emsssion measurements were also presented by Gullawme Plateas from LBNL, and used to measure the electron beam source size of a laser-plasma accelerator Sumultaneous measurements of electron beam spectra and divergence were taker with the single-shot CCD $x$-ray measurements and showed a correlation between $x$-ray and electron spectra

Stuart Mangles introduced results from expentments by a collaboration of lmpenal College London and the Lund Laser Center on Increasing the amplitude of the betatron oscillations in the wakefield by deliberately inducing an asymmetry Thus was done by adding the optical aberration coma to the laser spot [33] Thus could find potenisal application in increasing the $x$-ray flux from a betation soufce A number of results from the ALPHA-X project were 
presented by Dino Jeroszinski of the University of Strathclyde. Theste included measurements of MeV photons from the betatron source, characterization of the electron beam transwerse emitlance using a 'pepper-pot' techrique, and extremely short bunch durations, inferred from the coherent transition radialion spectrum (for related beam duration measurements by other groups sce the diagnostics section below), which indicated that the laser produced beams would likely be suitable for driving a compact free electrop laser.

Numerical afwancements were also presented, including betalton calculations using a post-processing diagnostic and eloctron trajectories fron the perticle-in-cell code OSIRIS [34] presented by Luis O'sitva from the Inslituto Superior Tennico. This technigue numerically calculated retarded potentials deposited on a 'virtual detector' in the farfield, giving an angularly resolved $x$-ray spectra and allowing the effects of realistic acceleration and beam dynamics on the $x$-ray source to be modeled. The diagnostic was used to numerically verify the results of Kneip, and also to predict the radiation from a $12 \mathrm{GeV}$ laser wakefield accelerator.

Laser wakefield accelerator-produced electrons are also now being injected into conventional magnetic undulators to produce radialion of potentially nartow bandwidth, which is a step towards the development of compact freeelectron lasers. Florian Grüner from Ludwig-Maximilians University presented the recent demonstration of a soft $\mathrm{X}$-ray undulator source at $20 \mathrm{~nm}$ driven by the stable wakefield accelerator beam at $200 \mathrm{MeV}$ presented by Karsch. He then discussed the steps towards a 'table-top' free electron laser using a laser wakefield accelerator, including the electron bearn stability, tunability and undulator requirements towards a "minimal demonstration" of a free electron taser [30]. One important aspect of this, which is also relevant to staging of the laser wakefield accelerator, is beam transport between the wakefield accelerator and the andulalor (or subsequent stages). Jens Osterhoff from LBNL and Raphael Weitgartner from Lodwig-Maximilians University both demonstrated that miniarre quadrupole permanent magnets could successfully miligate pointing fluetuations and beam divergence issues. Undulator radjation measurements can also be usted as an accurate diagnostic of the electron beam properties, as discussed by Michat Bakeman from LBNL. This is because the radiation peak entrgy, bandwidth and brightness depend on the electron bean charge, peak energy and energy spread, and provide diagnostics of longitudinally slice-resolved parameters in addition to the bulk beam propenties.

Finally, Bernharơ Hidding from Heinrich-Heine University presented a possible novel applieation for laser driven sources, in testing space components exposure to the sort of radiation fluxes that exist outside of the earth's magnetosheath. Since lasers routinely produce intense fluxes of ions, electrons and photons, and are relatively inexpensive and compact, they may prove to be an excellent test-bed for space electronic devices.

\section{BEAM PROPERTIES AND DIAGNOSTICS}

The micron-scale acceierating stuctuse of laser-plasma accelerators forms naturally ultrashort, intense electrón bunches, and diagnostic techniques to analyze the wake structure, electron bunch, and the propagation and evolution of the laser pulse are advancing rapidly.

Measurement of the fs-scale electron bunch has been a focus of recent research. Coherent transition radiation measurements showing a 1.5 fs long electron bunch produced by coliding pulse experiments were presented by Victor Malka of LOA. Photon yicld per electron was measured and incicated emission was coherent, and fiting to the spectrum was used to infer bunch length of $1.5 \mathrm{fs}$, which is close to that predicted by particlo simulations for these paramelers. Related data was presented by Jaroszinski, above, and in Fiorito and Lin's presentations in WG 5. Transverse oscillations of the electron beam atuibuted to the laser field were shown by Hideyukj Kotaki of JAEA, and analysis indicaled the electron beam length was in the $4 \mathrm{fs}$ range. THz diagnostics [35] were presented in a related plenary by Nicholas Matlis of l.BNL. Measurement of beam charge for the intense ultrashort bunches has also been a subject of community discussion, and Kei Nakamura presented results of calibration belween integrating charge transformers, LANEX phosphor screens, button type BPMs, and radionucikie activation measurements. It was shown that these techniques are in agreement for both RF accelerator and broad-band laser-plasma accelerator beams and for 0.1 - $1.5 \mathrm{GeV}$ energies. Related calibrations were presentelf by schrartu from FZD. Pepper pol measumements of beam emittance at the $2 \pi$ mum-mrad level were presented by Veisz, and use of calorinetery to measure GeV e-bearns was discussed by Wang.

The transient plasma nature and small scale of the accelerator structure in laser-plasma accelerators present chalIerges to measurement, and until recently structure had been inferred from output electron and laser beam characteristics. New diagnostics were discussed which directly measure the plasma wake structure. An extension of the wake holography technique \{36\} was described by Zengyn $\mathrm{Li}$ of $\mathrm{U}$. Texas, showing that by using multiple lines of sight, evolving wake structures can be recovered, which are those of greatest interest for acceleration since driver pulse evo- 
iutorn is often umportant Ths was tested using a Kerr mediam, demonstrating the recovery method, and is now ready for implementation to measure stakefields The 'trapping' of a co-propagatung probe by the plasma bubble was also measured by the UT gtoup, presented by Peng Dong, and AM reconstrucuon of the optucal phase was used to infer bubble structure and polential as an optacal compressor Polarograms un which polarzation rotalion of a probe laser pulse due to the magnetic fiejd of the wake structure xs measured, were shown by Malte Kaluza of Jenta, and were used to measure the bubble structure Beam hosing was also measured usung a side scatler diagnosuc Wake sineture was charactenzed using a cone of forward-ditected 2- $\omega$ light in results presented by Drntrny Kaganovich of NRL Ring angle and thickness were correlated to experımental parameters and sumulation resuits, providing a diagnostic of the bubble sheath parameters incleding cases in which the laser pulse overlaps two wake buckets The relation of emussron to electron unjection and laser polarization was discussed

Laser evolution and scattering was discussed in several talks Forward Raman scattenng in intense laser pulses longer than a plasme period, in the regime relevant to duect laser acceleration, was analyzed by John Palastro of U Maryland It was shown that while Raman growth wrould be problematec for such pulses in uniform plasmas, the introduction of modulated plasma densities as described by Layer for quast-phase matching of the acceletation also delunes FRS preventigg growth Transsutted optical spectra were analyzed in the Oxford expenments and simulations, and it was shown that taking into account a relativistic shift un the Ramar spectrum slowed dependence of the Raman stift with density and improved agretment wilh data, as presented by Bourgeouis and Hooker McGuffey of Michigan presented results on relatuvistic effects on sidescatter Gouling of the laser pulse through capillary structures and the effects of self and channel guiding were unvestigated using a wavefront sensor, in results presented by Satom Shuraski at LBNL. The use of such a sentsor eltminates ambiguties in waveffont eurvature present in spot-camera based analyses, allowing more precise snalysis Analysis of the interaction of plasma and electromagnetic waves towards dragnastics of bearn emittance was presented by Arnesto Bowman of Flonda A\&M

\section{UPCOMING FACILITIES}

Many new facilities are planned to extend laser-plasma accelerator research in comng years The FZD laboratory is combiting a $150 \mathrm{TW}$ lastr with a superconducung electron linac to enable external injection of the linac beam inte the wake as well as Thonson scatterung experments, as presented by Ulrach Schramm Novel technuques for tilted phase fronts in lune-focused laser beams were presented to increase Thomson yield The CALA facility was outluned by Stefan Karsch of LMU and MPQ, and will Include a compact sychrotron, $3 \mathrm{PW}$ laser, and a $100 \mathrm{TW} / \mathrm{ikHz}$ laser for synchromized laser and beam sources The BELLA facilty at LBNL, which targets hugh-energy physics and lught-source relevant stages at the $10 \mathrm{GeV}$ level, was described in a related plenary talk by Wim Leemans

\section{CONCLUSIONS}

The presentasots and discussions in the working group demonstrate the contunued rapid progress of laser plarma accelerators in beam quality, stability, and in the physical understanding and diagnosnes which underiay these In particular, the past two years have seen widespread work on control of injection through both better understanding of self trapping by the wake, and separare control of injection via colliding laser pulses, density transitions and touzation. umproving experimental control over and theoretical understanding of the beams Controlled injection in turm allows tuning of the acceleritor structure To enable thıs, the effects of twon-gaussian laser modes on the acceleration process, and the interaction of self and plasma channel guiding are bentg characterized Simulations and theory are also beginning to prowide predictuve guidance to desugn experiments as well as increased fidelity in understanding and controfiling the processes observed New dragnosucs access cvolving wakes and resolve bunch and wake structure These developments set the stage for new facilities and expeninepts to develop laser-plasma accelerators

\section{ACKNOWLEDGMENTS}

We thank the particjpants in the working group for contrtuling the matmial summarized here, and for productive workshop discussions explonng these topics References and acknowledgments for the work descnbed herein can be found in the respective papers in these proceedings 


\section{REFERENCES}

1 T Tajuma, and J M Daursin, Phys Rev Lett 43, 267-70 (1979)

2 J Faure, Y Glinec, A Pukhov, S Kisejey, S Gordıenko, E Lefebrre, J .P Rousseau, F Burgy, and V Malka, Nature 431, $54 I-544$ (2004)

3 C O R Goddes, Cs Toth, J van Tilborg, E Esarey, C 8 Schroeder, D Bruhwiler, C Nieter, J Cary, and W P Leemant, Nature 431, 538-541(2004)

4 S P D Mangles, C Murphy, Z Najmudin, A Thomas, J Collıer, A Dgngor, E Divali, P Foster, J Gilacher, C Hooker, D Jaroszynsk1, A Langley, W Mon, P Nocreys, F Tsung, R Viskup, B Walton, atłd K Krushelnuck, Narkre 431, 535-538 (2004)

5 W P Leemans, B Nagler, A J Gonsalyes, C Toth, K Nakamura, C G R Geddes, E Esarey, C B Schroeder, and S M Hooker, Nat Phys 2, 696-699 (2006)

6 J Faure, C Rechaur, A Norlın, A Lifschitz, Y Gilince, and V Malka, Nature 444, 737-739 (2006)

? C G R Geddes, K Nakamura, G R Plategu, Cs Tóth, E Comer-Michel, E Esarey, C B Schroeder, J Cary, and W P Leemant, Phys Rev Lett 100, 2150014 (2008)

8 J Osimhoff, A Popp, Z Major, B Marx, T P Rowlands-Rees, M Fuchs, M Geissler, R Horleın, B Hidoliti, 5 Becker, E A Peralta, U Schramu, F Grumer, D Habs, F Krausz, S M Hooker, and S Karsch, Phys Rev Letr 101,085002 (2008)

9 D H Froula, C E Claylon, T Doppter, K A Marsh, C P J Barty, L Divo, R A Fonsecá, $S$ H Gletzer, C Josh1, W Lu, S F Marums, P Michel, W B Mon, J P Palastro, B B Pollock, A Pak, J E Kalph, I S Ross, C W Siders, L O S1]va, and T Wang, Phys Rev Letr 103, 215006 (2009)

10 K Shumoda, Appled Optes 1, 1479-1484 (1962)

II A G York, H M Michberg, J P Palastro, and T M. Antonsen, Phys Rev Leth 100, 195001 (2008)

12 A Modena, Z Najmudin, A E Dangor, C E Clayton, K A Marsh, C Josh, Y Malka, C B Darrow, C Danson, D Necly, and F N Walsh, Nature 377, 606-608 (1995)

13 F S Toung. R Narang, W B Mon, C Joshi, R A Fonseca, and 2, O Silva, Phys Rev Lett 93, 195002 (2004)

14 S Bulanov, N Natumoya F Pegoraro, and J Saka, Phys Rev E 58, R5257 (1998)

15 E Esarey, R F Hubbard, W P Leement, A Ting, and P Sprangle, Phys Rzv Lett 79, 2682-2685 (1997)

I6 G Fubiam, E Esary, C B Schroder, and W P Leemans, Phys Rev E 74, 016402 (2004)

17 M Chen, Z -M Sheng, Y.Y Ma, and I Zhang, Jowrnat of Appded Phystes 99, 056 109 (2006)

18 T P Rowlands-Rees, C Kampendis, S Knesp, A J Gonselves, S P D Mangles, I O Gollacher, E Bnunetw, T Ibbotson, C D Muphy, P S Foster. M J V Steeter, F Budde, P A Norreys, D A Jatoszynska, K Krusheltick, Z Najmudın, athd $S$ M Hooker, Phys Rev Lets 100, I0S000 (2000)

19 C McGuffey, A G R Thomas, W Schtmaker, T Malquaka, V Chrykow, F J Dollar, G Kalıntchenko, V Yenovsky, A Maksunchuk, K Krushelsuck, V Y Bychenkov, I V Glazynn, and A V Karpees, Phys Rev Lett 104, 025004 (2010)

20 A Pak, K A Marsh, S F Mardun, W Lu, W B Morn, and C Josh, Phys Rev Lar 104, 025003 (2010)

2I C E Clayron, J E Ralph, F Albert, R A Fonsecte, S G Glenzer, C Joshi, W Lu, K A Marsh, S F Martus, W B Mort, A Pak, F S Tsung. B B Pollock, J S Ross, L O Silva, and D H Froula, Phys Rev Lett occepted (2010)

22 D I Spence, and S M Hooker, Phys Rev E 63, 01540I(R) (2O)I)

23 B Cros, C Courtors, G Mathueussent, A D Bemardo, D Balati, N Andreev, and S Kuznet5oy, Phys Rev E 65,026405 (2002)

24 E Esarey, P Sprangle, J Krall, and A Ting, IEEE / Quantwm Electron 33, 1879-914 (199T)

25 C B Schroeder, E Esarey, C G R Geddes, C Toth, and W P Leentans, Proc Adv Acc Con Wkstap pp 2083-21d (2008)

26 T Hosokaı, K Kinoshuta, A Zhudkov, K Nakamura, T Watasabe, T Ueda, H Kotakı, M Kando, K Nakajuma, and M Uesaka, Phys Rev E 67,036407 (2003)

27 P Sprangle, B Hafizi, I R Pesano, R F Hubbard, A Ting, C I Moorc, D F Gordon, A Zigler, D Kaganoyich, and T M Antonsen, Jr, Phys Rew $E$ 63, 056405 (200I)

28 E Cormuer-Hyichel, E E andC G R Geddes, C B Schroeder, and W P Loemens, Phys Rev ST AB (subrutled)

29 C B Schroeder, W M Fawley, F Gnuener, M Bakeman, K Natamuta, K E Robrnson, Cs Toth, E Esarey, and W P Leemans, Proc Adv Acc Con Weshp pp 637-42 (2008)

30 M Fuchs, $R$ Wengartner, A Popp, Z Major, S Becker, J Osterhof, 1 Cortine, B Zentler, R Hoerlen, O D Tsakutis, U Schramm, T P Rowlands-Rees, S M Hooker, D Habs, F Krausz, S Karsch, and F Gruener, Nat Phys 5, 826 (2009)

3I A Rousse, $K$ T Phukx, $\mathbf{R}$ Shah, A Pukhov, E Lefebvre, $\checkmark$ Malka, S Kuselev, F Burgy, J -P Rousseau, D Umstadter, and D Hulin, Phys Rev Lett 93, 135005 (2004)

32 R W Schoenlein, W P Leemars, A H Chn, P Volfbeyn, T E Gover, P Balling, M Zolototer, K I Kum, S Chaltopadhyay, and $C$ V Shathk, Scaence 274, 236-8 (1996)

33 S P D Mangles, G Genoud, S Kneip, M Butca, K Cassou, B Cros, N P Dover, C Kampendis, Z Naj11udim, A Persson, J Schurciber, F Wojda, and C G Wahlstrom, Appt Phys Lent 95 (2009), 1SSN 0003-6951

34 J L Marturs, S F Martins, R A Fotseca, and L O Silva, "Radiatton post-processing in PIC codes." SPIE. 2009. vol 7359. p 73590)

35 J van Tilborg, C B Schroeder, C V Filıp, Cs Toin, C G R Geddes, G Fubian, R Huber, R A Kaindl, E Esarry, and W P leertums, Phys Rev lett 96,014801 (2006)

I6 N H Malls, S Reed, S S Bulanov, V Chyykov, G Kalıntehenko. T Matsuoka, F Rousseau, V Yanovsky, A Maksimchuk, S Kalmykov, G Shvets, and M C Downer, Nat Phys 2, 749-753 (2006) 


\section{DISCLAIMER}

This document was prepared as an account of work sponsored by the United States Government. While this document is believed to contain correct information, neither the United States Government nor any agency thereof, nor The Regents of the University of California, nor any of their employees, makes any warranty, express or implied, or assumes any legal responsibility for the accuracy, completeness, or usefulness of any information, apparatus, product, or process disclosed, or represents that its use would not infringe privately owned rights. Reference herein to any specific commercial product, process, or service by its trade name, trademark, manufacturer, or otherwise, does not necessarily constitute or imply its endorsement, recommendation, or favoring by the United States Government or any agency thereof, or The Regents of the University of California. The views and opinions of authors expressed herein do not necessarily state or reflect those of the United States Government or any agency thereof or The Regents of the University of California.

This work was supported by the U.S. Department of Energy under Contract No. DE-AC02-05CHII23I. 